\title{
A longitudinal study in atypical Cri-du chat profile: A single case report
}

\author{
Maria Rosa Pizzamiglio ${ }^{1}$, Cristino Volpe ${ }^{2}$, Laura Piccardi ${ }^{1,3^{*}}$ \\ ${ }^{1}$ Centro Ricerche di Neuropsicologia, IRCCS Fondazione Santa Lucia, Rome, Italy; \\ ${ }^{*}$ Corresponding Author: laura.piccardi@cc.univaq.it \\ ${ }^{2}$ Servizio di Riabilitazione Infantile, IRCCS Fondazione Santa Lucia, Rome, Italy \\ ${ }^{3}$ Dipartimento di Medicina Interna, Sanità Pubblica, Scienze della Vita e dell'Ambiente, Università degli Studi dell'Aquila, Coppito, \\ Italy
}

Received 29 November 2012; revised 1 April 2013; accepted 16 April 2013

Copyright (C) 2013 Maria Rosa Pizzamiglio et al. This is an open access article distributed under the Creative Commons Attribution License, which permits unrestricted use, distribution, and reproduction in any medium, provided the original work is properly cited.

\begin{abstract}
Background: Cri-du-Chat Syndrome (CdCS) is a rare genetic disorder characterized by a severe mental delay, minimal verbal abilities and severe learning difficulties. Methods: Here, we report two neuropsychological assessments of an Italian girl (FS) with CdCS who was affected by a moderate mental delay. The first assessment was made at 2.3 years and second at 6.5 years. Results: Her cognitive profile was characterized by a discrepancy between social-communicative and visual-motor skills. Specifically, her linguistic skills were better than her ability to copy a drawing or play with a set of building blocks. FS showed good lexical competence in both comprehension and production. Differently, her grammatical skills (i.e. comprehension and production) were somewhat defective. Conclusion: The FS's case, due to her moderate mental delay and her preserved linguistic skills, allowed investigating some aspects of this syndrome never explored before.
\end{abstract}

Keywords: Cat Cry Syndrome; 5p-Syndrome; Narrative Discourse; Longitudinal Study; Mental Delay

\section{INTRODUCTION}

Cri-du-Chat syndrome (CdCS) is a rare chromosome disorder that is caused by deletion of the short arm of chromosome 5 (5p-). It affects from 1:20,000 to 1:50,000 live births [1-3]. Patients with CdCS show large phenotype variability due to the size of the chromosome portion deleted, as hypothesized by Cerruti Mainardi et al.
[4]. In fact, these authors demonstrated a direct relationship between size of the deletion and severity of the psychomotor delay.

Clinical features include some facial dysmorphias, visceral malformations, microcephaly, larynx abnormalities causing phonatory disorders, and a high-pitched monotonous cat-like cry that is almost always present in newborns. Cognitive development is characterized by severe mental and psychomotor retardation [1].

Several studies have suggested a triad of characteristics: psychomotor delay, minimal verbal abilities, and severe learning difficulties [e.g. 5,6]. Patients with CdCS have a short attention span. They are also hyperactive and show stereotypical, aggressive, and self-injurious behavior patterns [7]. Cornish and colleagues [6], who were the first to use standardized neuropsychological tests to obtain a systematic evaluation of psychological development in CdCS, described severe language delay characterized by dissociation between less impaired comprehension and very defective production. Nevertheless, very poor verbal production does not prevent communication. In fact, some studies have reported that over $50 \%$ of CdCS individuals use non-verbal language to communicate their needs $[6,8,9]$. In a critical review of speech and language development in CdCS, Kristoffersen [7] confirmed the finding reported in many studies that not all individuals with CdCS are able to use spoken language as a means of communication. He concluded that there is still too little knowledge about language abilities in CdCS and that further studies are needed to investigate the relationship between linguistic and nonlinguistic factors [7]. Moreover, previous studies analyzed verbal and linguistic abilities and paid little attention to the other non verbal neuropsychological domains that are so important for autonomy in daily life (see for example [6]). 
Pizzamiglio and co-workers [10] suggested a discrepancy between verbal and non-verbal abilities in this syndrome. These authors described six Italian children affected by typical CdCS who clearly showed dissociation between good communication ability and very pathological hand-eye coordination ability. This observation is supported by a previous report of a single case that showed a difference between normal Verbal IQ and very defective Performance IQ [11]. An interesting anatomical finding that supports this type of dissociation is the presence of brainstem atrophy, mainly at the pontine level, associated with a small cerebellum, and atrophy of the middle cerebellar peduncles and cerebellar white matter [12]. These results, like those observed in patients with olivoponto-cerebellar atrophy, are correlated with the presence of a deficit in coordination and with a developmental delay in motility, as observed in CdCS patients [12].

Here, we describe in detail the case of a child with Cri-du-Chat Syndrome who had a moderate mental delay when assessed at 2, 3 and 6 years of age in a Developmental Neuropsychological Centre (I.R.C.C.S. Fondazione Santa Lucia, Rome). Since the child had only a moderate mental delay, we were able to make a more thorough investigation of several aspects of her neuropsychological profile observed longitudinally. First, we found a clear discrepancy between good linguistic abilities and poor non-verbal ones (such as hand-eye coordination and visual-motor integration). Second, unlike other CdCS's cases, FS's spoken language was rich and she used the lexicon appropriately. By contrast, her grammatical skill was severely damaged. Therefore, we also investigated an aspect of language that has been neglected in the CdCS literature [7], that is, syntactical skills (both comprehension and production), by looking for the presence of typical errors. Indeed, FS's syntactical performance seemed to be influenced by semantic and reasoning factors. This case supports previous results in which a more severe delay in non-verbal abilities with respect to communicative skills has been showed in a group of CdCS subjects with severe mental delay [10]. Moreover, the presence of a well-structured language allows us to deeply evaluate other verbal characteristics otherwise never explored before. Given that there are relatively few accounts of CdCS's children with higher cognitive ability, this paper certainly had the potential to make a useful contribution to the literature. This particular case would appear to be consistent with earlier reports suggesting greater variability of intellectual ability within the syndrome than was once thought [13].

\section{CASE REPORT}

FS is the second child of Italian parents. She was born during the fortieth week of a normal pregnancy; delivery was regular.

Her neonatal assessment was as follows: $2.880 \mathrm{~kg}$. birth-weight, $44 \mathrm{~cm}$ in length, $32.9 \mathrm{~cm}$. head circumference, abdominal hernias, cardiac murmur, stridor breathing, light pulmonary dysplasia.

Subsequent pediatric investigations indicated a highpitched cat-like cry, prolonged expiration, frequent rhinitis, ear infections, dermatitis, and an allergy to milk.

A neurological assessment at 9 months revealed hypotonia, divergent strabismus, poor coordination, attention deficit, hyperkinesis, and hypersensibility to peculiar noises. No cardiovascular diseases or neurological anomalies were present. In fact, her electroencephalogram and echoencephalography were normal. She also showed a psychomotor delay. FS was able to be sitting by herself at 14 months and she started to walk alone at 22 months. She spoke her first words at 13 months. The diagnosis of Cri-du-Chat Syndrome was karyotypically confirmed when she was 17 months old. The molecular analysis identified a terminal deletion of $5 \mathrm{p} 15.2 \mathrm{pter}$ "de novo", including the critical region of the syndrome (Cattedra di Genetica Medica-Prof. B. Dalla Piccola-"Sapienza" University of Rome and San Camillo-Forlanini Hospital, Rome).

When she was two years and three months old, FS was assessed for the first time at the Developmental Neuropsychology Unit of the I.R.C.C.S., Fondazione Santa Lucia in Rome. She showed severe hyperkinesis and attention deficits, particularly when she had to orient her attention toward the environment. Her attention deficits caused frequent falls, weariness, and poor quality play that was suddenly abandoned to start a new game. She also showed behavioral disorders characterized by inconsolable crying without reason. Although her behavior was typical of CdCS individuals, she showed neither strong dimorphisms nor microcephaly, which could explain the late diagnosis. We assessed FS on two separate occasions, four years apart. During this period, the child received a discontinuous cognitive therapy due to frequent moving for parents' working problems.

Written informed consent, approved by the local ethical committee, was obtained from FS's parents on occasion of both neuropsychological evaluations.

\section{NEUROPSYCHOLOGICAL EVALUATION}

FS was assessed on two separate occasions, four years apart.

\subsection{First Assessment-2 Years and 3 Months of Age}

\subsubsection{Cognitive Functioning}

At the first assessment, the child's mental develop- 
ment was assessed using Griffiths' Mental Development Scales (GMDS 0-8: [14]). We administered these scales to verify the presence of asymmetries in cognitive development. The scales include separate independent subscales that allow analyzing different cognitive areas. Each subscale includes several trials to evaluate different ability levels. The first subscale measures Locomotor development (LD). Using this scale, it is possible to check for the presence of physical weaknesses, disabilities, or more specific motor deficits in young children. The second subscale measures Social and Personal (SP) abilities, such as symbolic play and affective and need communication. The third subscale measures Hearing and Speech (HS) by evaluating the quantity of verbal utterances (number of syllables or words in a phrase) and the ability to perform actions upon verbal command. The fourth subscale assesses Hand-eye Co-ordination (HEC). For example, it evaluates fine hand movements, the use of the index finger for pointing, and the ability to build a 4-block tower or hold a pencil to make a mark on a sheet of paper. The fifth and last subscale measures Performance (P) abilities, including the development of visuospatial representation and visuo-motor coordination (for example, putting a square and a circle in the appropriate holes on a board or opening a screw toy).

FS's profile was generally low. She has a Mental Age of 17 months and a General Quotient of 63. Her highest score was in Hearing and Speech and her lowest in Eye and Hand Coordination. Figure 1 shows FS's z-scores on each scale.

\subsubsection{Language Abilities}

Language development was assessed using the MacArthur Communicative Development Inventory (adapted Italian version, [15]) to obtain an evaluation of FS's expressive and receptive language skills via maternal reports. The questionnaire has two forms: "Gestures and Words" and "Words and Sentences". Here, we used only the former, which assesses language abilities in 9- to 17-month-old children. Although it was not appropriate for FS's chronological age, it was more sensitive for investigating her language and communicative abilities. Indeed, "Gestures and Words" assesses both word/gesture comprehension and gesture production, whereas "Words and Phrases" assesses only the production of words and sentences. The Gestures and Words Questionnaire consists of two parts. The first part includes a checklist of 408 words, divided into 19 categories; it includes nouns, predicates, and function words. The second part includes 63 communicative and/or symbolic gestures, which are also divided into categories (such as representational gestures, routines, etc.). The results of the questionnaire revealed the following: FS's comprehension of 12 sentences was the same as that of a $10-11$ months old; her comprehension of 123 words was the same as that of a 14 - 15 months old; her production of 10 words corresponded to that of a $12-13$ months old; and her production of 49 gestures was the same as that of a 16 - 17 months old. A qualitative analysis of her performance showed that FS was able to understand routine sentences but failed to understand the grammatical aspects of language (such as articles, pronouns, and adverbs).

\subsection{Second Assessment-6 Years of Age}

\subsubsection{Cognitive Functioning}

We assessed FS's intellectual ability with the Wechsler Preschool and Primary Scale of Intelligence (WPPSI: [16]). We chose this instrument because it was appropriate for her chronological age and could distinguish between the verbal and performance components that appeared dissociated at the first assessment. The evaluation showed that FS had a Full Scale IQ of 52, a verbal IQ of 67 , which was significantly higher $(p<0.05)$ than performance $(<50)$. Table 1 reports the results obtained in each subtest.

On the verbal scale, FS's highest score was on "Similarities". In fact, her performance on this subtest was

Griffiths Scales

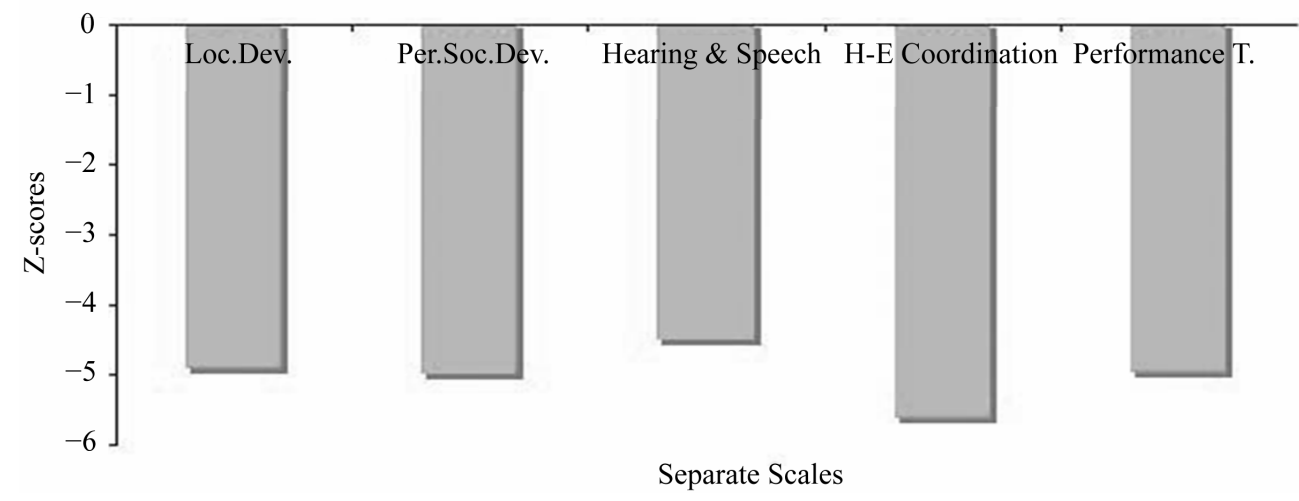

Figure 1. The graph shows FS's z-scores on Griffiths' scales. 
Table 1. Scaled scores in different WPPSI's subtests are reported.

\begin{tabular}{lccc}
\hline Subtests: & Scaled Scores & Subtests: & Scaled Scores \\
\hline Verbal Scale (IQ = 67) & & Performance scale (IQ < 50) & 1 \\
Information (I) & 4 & Animal House (AH) & 8 \\
Vocabulary (V) & 7 & Picture Completion (P) & 1 \\
Arithmetic (A) & 1 & Mazes (M) & 3 \\
Similarities (S) & 11 & Geometric Design (G) & 2 \\
Comprehension (C) & 3 & Block Design (B) & \\
FULL SCALE (IQ = 52) & & & \\
\hline
\end{tabular}

significantly different from her performance on the others $(p<0.05)$, particularly "Arithmetic" and "Comprehension". On the performance scale, her best result was in "Picture Completion". In fact, she performed within the normal range and her score was significantly higher on this sub-test than on the others $(\mathrm{p}<0.05)$.

\subsubsection{Language Abilities}

1) Receptive vocabulary

We tested FS's verbal comprehension using the Peabody Picture Vocabulary Test (PPVT: [17]). This test allows measuring the receptive vocabulary of children (aged 2.5 years and older) and adults. It consists of 175 items of increasing difficulty presented as plates. Each plate contains four pictures. FS was asked to choose the picture (out of four options) that corresponded to the stimulus word. Although her chronological age at the time was 5.9 years, she obtained an extremely high score, equal to that of a 6.6 years old child. She made 21 errors: 8 errors on the names of things or people (sail, hook, barber, beehive, shoemaker, corn shock, observatory and oasis); 4 errors on actions (to cook, to spy on, to ski and to solder); 6 errors on abstract words (time, temperature, balance, discussion, idol, autumn) and 3 errors on feelings (horror, disappointment and surprise).

2) Grammatical comprehension

We tested FS's verbal comprehension using the TCGB (Test of Grammatical Comprehension for Children; [18]). Her performance was in the bottom tenth percentile (see Table 2).

TCGB assesses grammatical comprehension in children from 3.6 year old to 8 year old. It is a multiplechoice test that requires selecting a picture to match a sentence spoken by the examiner (see Figure 2 for examples of items).

The vocabulary in all items (76) is simple. Grammatical complexity increases as the test proceeds, from locative structure to active, passive, negative, dative, and relative clauses. Each type of structure is acquired at different time of development and contains different grammatical characteristic. For example, in the Locative structure clauses with a prospective characteristic have a higher level of difficulty than topological ones. Indeed, in prospective structures the subject has to make a judgment about relationships between objects and has to interpret the situation, while in the topological structures the subject has to evaluate just the spatial relationship about elements. Children acquire prospective structures only around 6 years of age [19]. In grammatical development, inflections relative to gender and number are acquired sooner around 3.6 years and are easier than inflections relative to verbs. Positive active sentences (reversible, probable/improbable, and neuter) are grammatically complicated because the difficulty is linked to interference between the correct grammatical structure and the child's world knowledge in which the animate agent acts on the inanimate agent and not vice versa. The most difficult negative sentences are both the non-reversible, active ones with alternative objects and the negative, reversible ones. In fact, in these types of sentences agent $\mathrm{X}$ does not perform the action on agent $\mathrm{Y}$; instead, $\mathrm{Y}$ performs it on $\mathrm{X}$, and this kind of operation requires deductive reasoning. The difficulty in the positive, improbable, reversible, passive sentences' comprehension is due to syntactic and cognitive factors; the syntactical difficulty increases when improbable events are present. In this type of sentence, the difficulty is not only at the syntactical level but also at the perceptualcognitive level. For example, in the sentence "the wastepaper basket has not been emptied" the child has to deduce that the wastepaper basket has not been emptied because it is full.

Here, the great difficulty is that the object/subject components can change roles and, therefore, meaning. Moreover, the length of the sentence requires overloading the working memory system, which has still not reached maturity.

A more detailed analysis of FS's errors revealed a general deficit for all types of clauses. Percentage of error produced by FS for each type of clauses is reported in details in Table 2.

3) Spontaneous language during a play situation

While FS played with a little house that had furniture and Lego characters, we recorded her spontaneous 
Table 2. Percentage of errors for each type of clauses and examples of errors made by FS are reported. Each score obtained by FS are $\leq 10$ percentile.

\begin{tabular}{|c|c|c|c|c|c|c|c|}
\hline \multicolumn{8}{|c|}{ TYPE OF CLAUSES: } \\
\hline Locative & Inflectional & Positive Active & Negative Active & Positive Passive & Negative Passive & Relative & Dative \\
\hline $\begin{array}{l}64,29 \% \\
\text { Topological } \\
\text { (i.e. "the cat } \\
\text { is close to the } \\
\text { chair"); } \\
\text { Prospective } \\
\text { (i.e. "the dog } \\
\text { runs from the } \\
\text { house to the } \\
\text { tree"). }\end{array}$ & $\begin{array}{l} \\
\text { 25\% } \\
\text { (i.e. FS } \\
\text { pointed "il } \\
\text { bambino } \\
\text { disegna" = } \\
\text { the child } \\
\text { draws instead } \\
\text { to "il } \\
\text { bambino } \\
\text { disegnerà" = } \\
\text { the child will } \\
\text { draw). }\end{array}$ & $\begin{array}{l}80 \% \\
\text { Reflexive } \\
\text { (i.e. "the child } \\
\text { combs her hair"); } \\
\text { Neuter } \\
\underline{\text { Reversible }} \\
\text { (i.e. "the boy } \\
\text { pushes the girl"); } \\
\text { Improbable } \\
\text { Reversible } \\
\text { (i.e. "the child } \\
\text { d spoon-feeds the } \\
\text { mother"); } \\
\text { Probable } \\
\text { Reversible } \\
\text { (i.e. "the mother } \\
\text { combs the } \\
\text { child"); } \\
\text { Inanimate } \\
\text { Agent-active } \\
\text { (i.e. "the ball hits } \\
\text { the child"). }\end{array}$ & $\begin{array}{l}83.33 \% \\
\frac{\text { With subject plus }}{\text { verb (i.e. "the child }} \\
\text { does not sleep"); } \\
\frac{\text { Non-reversible }}{\text { without verb }} \\
\text { (i.e. "the cat does not } \\
\text { eat fish"); } \\
\text { Non-reversible with } \\
\text { alternative object } \\
\text { (i.e. the sentence is } \\
\text { "the child does not } \\
\text { eat soup" and the } \\
\text { only possible picture } \\
\text { to point is the child is } \\
\text { eating ice-cream); } \\
\text { Reversible } \\
\text { (i.e. "the girl does not } \\
\text { push the boy"). }\end{array}$ & $\begin{array}{l}100 \% \\
\text { Non-Reversible } \\
\text { (i.e. "the car is } \\
\text { washed by the } \\
\text { child"); } \\
\text { Reversible } \\
\text { (i.e. "the child is } \\
\text { dressed by its } \\
\text { mom"); } \\
\text { Neuter } \\
\text { Reversible } \\
\text { (i.e. "the dog is } \\
\text { dragged by the } \\
\text { man"); } \\
\text { Improbable } \\
\text { Reversible } \\
\text { (i.e. "the mom is } \\
\text { t taken in the } \\
\text { child's arms"). }\end{array}$ & $\begin{array}{l}\text { W6.67\% } \\
\text { With subject plus } \\
\text { verb (i.e. "the } \\
\text { wastepaper basket } \\
\text { has not been } \\
\text { emptied"); } \\
\text { Non-reversible } \\
\text { without action } \\
\text { ("the pipe is not } \\
\text { smoked by the } \\
\text { Indian"); } \\
\text { Reversible } \\
\text { (i.e. "the boy is not } \\
\text { pushed by the girl"). }\end{array}$ & $\begin{array}{l}75 \% \\
\text { Final in which } \\
\text { object becomes } \\
\text { subject (i.e. "the } \\
\text { boy runs after a girl } \\
\text { who is riding a } \\
\text { bicycle"); } \\
\text { In which subject } \\
\text { remains subject } \\
\text { (i.e. "the child on } \\
\text { the table is eating } \\
\text { the marmalade"); } \\
\text { Final in which } \\
\text { object remains } \\
\text { object } \\
\text { ("the father holds } \\
\text { the balloon that the } \\
\text { child broke"); } \\
\text { In which object } \\
\text { becomes subject } \\
\text { ("The flower pot the } \\
\text { child is painting is } \\
\text { on the chair"). }\end{array}$ & $\begin{array}{l}100 \% \\
\text { Neuter } \\
\text { Animate/inanimate } \\
\text { ("the girl gives the } \\
\text { schoolbag to the } \\
\text { boy"); } \\
\text { Probable Animate/ } \\
\text { animate/animate } \\
\text { ("the swallow } \\
\text { brings the worm to } \\
\text { the baby bird"); } \\
\text { Improbable, } \\
\text { Animate/animate/ } \\
\text { animate } \\
\text { ("the child brings } \\
\text { the cat to the } \\
\text { mouse"); } \\
\text { Improbable } \\
\text { Animate/inanimate/ } \\
\text { animate } \\
\text { ("the father brings } \\
\text { cigarettes to the } \\
\text { child"); } \\
\text { Probable Animate/ } \\
\text { inanimate/animate } \\
\text { ("the father puts the } \\
\text { shoes on the child"); } \\
\text { Neuter Animate/ } \\
\text { animate/animate } \\
\text { ("the dog brings the } \\
\text { pig to the sheep"). }\end{array}$ \\
\hline
\end{tabular}

production. Following there is a transcription of her discourse during the play situation:

FS: "We live there... here oh I am my mom's daughter...that Alessio is playing ball... this is the garden of the new house, we live here.... And that... mom Caterina here, Where is Francesca? Granny Gianna and Francesca and Caterina... the same color of hair like my mom! ... This is the cousin... this... and this is another little friend of Francesca. This is grandpa Renato and... this is Francesca's little friend, Francesco D... tatannn! This is a policeman that... that loves doughnuts that... look! What is this? How nice! That's him... that they invite him the policeman of a dinner... this... this is the kitchen... these are the bedrooms and of a nice dinner... Nooo! Mom's fallen down... it's the same! But where is the chair... Francesca... oh she fell down... This is mom and dad's bed and this oh! This is of Francesca's little friend. She is called Martina and this is Alessio P. and this is Martina... and but where was Francesca? But where is she? She fell down."

No phonological and only few grammatical errors were present in her spontaneous production. She misplaced some pronouns and used a possessive phrase instead of a dative one.
4) Phonological and Grammatical Production

We used "Le Storie Figurate" (Illustrated Stories), a subtest of an Italian battery called PFLI (Prove per la valutazione fonologica del linguaggio infantile: [20]) (Tests for the phonological evaluation of children's language). We have chosen to administer this subtest because it allows us to analyze a more complex verbal production. In fact in the other subtests, items are single picture and the require is just to name them. Differently, in this subtest several stories are depicted and the competence measured is not only a verbal production in which observes the presence of grammatical and phonological errors, but also the ability to understand the meaning of a story.

In the PFLI, the child is asked to describe illustrated stories. In this subtest, three stories depict three different everyday life situations (see Figure 3). We asked FS to tell the story presented in the pictures.

FS's language was poor and characterized by several grammatical errors but very few phonological ones. We can also observe that the meaning of her production was often inappropriate. She seemed unable to verbally process causal connections among the different scenes and introduced confabulatory elements and hackneyed 

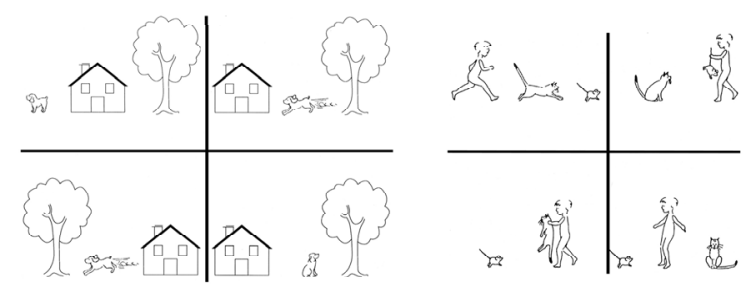

Locative Sentence

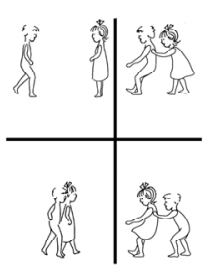

Positive Attive Sentence

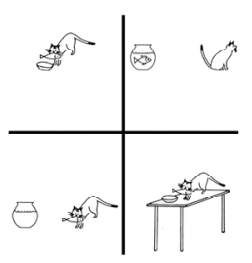

Negative Attive Sentence

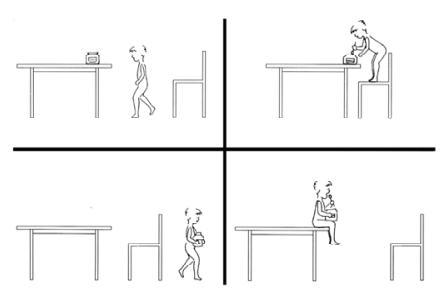

Relative Sentence

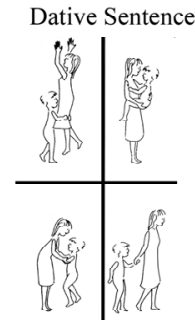

Positive Passive Sentence

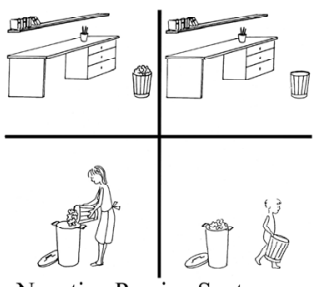

Negative Passive Sentence

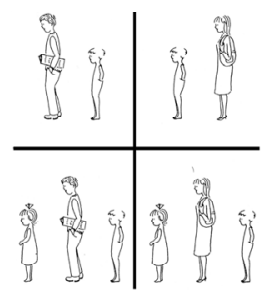

Inflectional Sentence

Figure 2. Examples of the different types of sentences in the TCGB test, on which FS failed.

phrases. In FS's speech, there is a contrast between correct, hackneyed phrases and idioms (i.e., The father has a brand-new car) and ungrammatical sentences, when she did not understand the meaning of the scene depicted (i.e. He takes it by the hand, he wanted by hand the balloon with line... burst.).

Moreover, several verbal perseverations are present in the stories. This shows her difficulty in disengaging from the previous story. For instance, she transferred some elements from the first story to the second one. She used the word "hat" instead of the word "balloon" and mentioned a strong wind in a picture that had nothing to do with wind.

From the analysis of her speech emerged the following phonological processes:

Stopping: where fricatives and affricates were replaced by a stop, such as "staba" instead of "stava" (she was);

Multiple processes: where FS used several processes at the same time within the same word, such as "Tesse"

Story 1

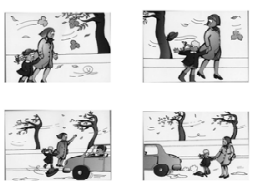

Story 2

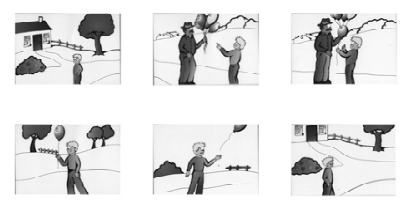

Story 3

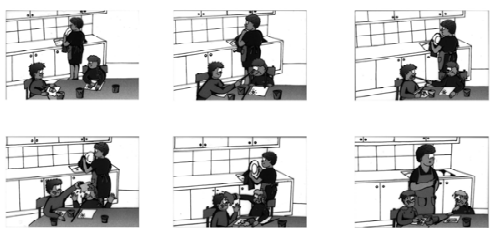

Figure 3. The three stories and FS's complete performance on each of them. In the Italian text, phonological errors are marked in bold. These types of errors are not translated into English. Story 1: "The girl comes back to home, but the mother because she goes to her mother's house. And the hat does not arrive at, because it does not arrive at. The father has a brand-new car. Ah! The hat gets a hole like a doughnut". ["La bambina a torna a casa, ma la mamma perché va a casa dalla sua mamma. E il cappello non si arriva, perchè non si arriva. Il papà c'ha una macchina nuova di zecca. Ah! Si buca come una frittella il cappello."]; Story 2: "The boy is going at home. He has a hat. He wanted the blue one. He wanted a balloon... the red one. He wanted a red balloon. He took it by hand, he wanted the balloon by hand with the string... burst. Burst the wind... ffffl ${ }^{1}$.. that he was going home". ["Il bambino staba andare a casa. C'ha un cappello. Voleva quello blu. Voleva un palloncino... quello rosso. Voleva un palloncino rosso. Lo tesse per mano, voleva per mano col filo il palloncino... scoppiato. Scoppiava il vento... ffffff... che andava a casa."]. In the Italian text, phonological errors are marked in bold. These types of errors are not translated into English. Story 3: "The mom, the children were working on. What are they doing? ... Work! The girl is all spot... but of pink, she spots all pink. She spots all colors. That to spot... she was about to spot. The mom, all the children were about to do a small job." ["La mamma, i bambini stavano a lavorare. Che cosa fanno? ... Lavoro! La bimba è macchia tutta... ma di rosa, macchia tutto di rosa. Macchia tutti i colori. Che a macchiare... stava per macchiare. La mamma, tutti $i$ bimbi stava a fare un lavorino."]

instead of "prese" (she took), showing the following:

-Cluster reduction, in which she simplified the consonant cluster by deleting one of them (pre instead of $t e$ );

${ }^{1}$ Onomatopoeic sound to indicate the sound of the wind. 
-Liquid gliding, where the liquid consonants were substituted by other consonants ( $t$ instead of $r$ ).

Very few articulatory disorders were observed except for fricatives substituting affricates (such as "Si" instead of "tçi").

Regarding grammatical production she made several errors. In particular, she inappropriately uses prepositions and conjuctions. She produced incorrectly the following type of sentences: inflectional; relative and positive passive. Further, she was unable to use the negative adverb (do not or is not) and she reduced her production using positive sentences. She also used intransitive verbs like transitive ones.

\subsubsection{Visual-Motor Abilities}

We assessed visual motor skills (i.e., visual and finemotor coordination skills) using the Full Format of the Visual Motor Integration Test ([21]; Italian edition: [22]), which presents drawings of geometric shapes arranged in order of increasing difficulty. The subject's task is to copy them.

FS's performance was very poor, that is, it corresponded to the fourth percentile. She was able to copy only the first five geometric shapes (the vertical, horizontal, and diagonal lines, the circle and the square). Her performance was under the 4 th percentile.

\section{DISCUSSION}

In the body of $\mathrm{CdCS}$ literature are very few accounts of children with relatively higher cognitive ability. This paper is an attempt to increase the knowledge on the cognitive aspects of this rare genetic syndrome. This particular case would appear to be consistent with earlier reports suggesting greater variability of intellectual ability within the syndrome than was once thought [13].

FS is a child affected by Cri-du-Chat Syndrome with a typical deletion of the short arm of the chromosome 5 including also the critical region with an atypical cognitive profile. In fact, she suffered from a mild to moderate mental delay. She was longitudinally assessed on two different occasions (at 2, 3 and 6 years of age). We report this case because the neuropsychological assessment revealed some interesting cognitive patterns. The moderate mental delay showed by FS and her linguistic abilities allowed us to investigate cognitive aspects never explored before, such as the grammatical competence. From a behavioural point of view, she had a short attention span and was hyperactive, consistently with her genetic disorder.

A discrepancy between verbal versus non-verbal skills lasting in both neuropsychological assessment emerged. Specifically, in WPPSI Scales emerged a significant difference between normal Verbal IQ and very defective Performance IQ. This observation is particularly inter- esting because supports two previous works, suggesting that the discrepancy between verbal and non-verbal abilities is a fundamental characteristic of this syndrome regardless the severity of the mental delay. Indeed, Pizzamiglio and co-workers [10] found the same discrepancy between verbal and non-verbal abilities in a group of six Italian children affected by Cri-du-Chat syndrome with a profound mental delay as well as Cornish [11] in a single case with high cognitive abilities.

To our knowledge, previous studies on $\mathrm{CdCS}$ have stressed the lack developmental linguistic skills and the presence of more preserved communicative skills. Cornish et al. [9] also described the presence of dissociation between better linguistic comprehension than linguistic production in this syndrome. Sohner and Mitchell [23] were the first to analyze the phonetic repertory of prelinguistic vocal development in a girl with CdCS. Subsequently, Kristoffersen [7] reported a longitudinal case study of consonant productions in a Norwegian girl with CdCS from 4.6 to 9.4 years of age. He found that throughout the period of observation she produced many articulation errors. Moreover, her consonant production was both delayed and deviant as compared with normally developing children. However, her errors decreased as she grew up. In our case, we observed both lexical and grammatical features that have never been explored before. FS's language was characterized by good articulation and quite good phonological production. With regard to comprehension, her vocabulary was comparable to her chronological age. This was shown by her performance on the Peabody Vocabulary test, in which her mental age was actually higher than her chronological age. FS spoke her first words at the regular milestones of linguistic development. Successively, she also used refined terms with a poor sentence's structure. Indeed, FS's grammatical speech structure was particularly deficient if compared with that of normally developing children. This profile was already present at her first language assessment, when she was administered MacArthur's Questionnaire. In fact, grammatical comprehension was the most impaired aspect on this assessment instrument. At the second assessment, she produced different types of grammatical errors related to the complexity of the linguistic content in the situations elicited (see for instance the illustrated stories versus her spontaneous language). This was also true for comprehension, as evidenced by her performance on the TCGB. We also observed that in the illustrated stories her speech was adequate when she used idioms or hackneyed phrases but became confabulatory when she had to explain causal relationships or the logical coherence of a story.

In conclusion, the FS's neuropsychological profile is characterized by a language, developed following the normal milestones, characterized by preserved lexical, 
phonological and articulatory competences, but with grammatical disorders. This rare cognitive profile allows deeply testing linguistic aspects generally neglected. An open-ended question is: could be grammatical deficits showed by FS a marker of the high-functioning CdCS's profile? Unfortunately, to our knowledge this aspect was not assessed in the other high-functioning case described in literature by Cornish [11]. Only other cases like that could shed some light on this question.

\section{REFERENCES}

[1] Neibuhr, E. (1978) The Cri-du-Chat syndrome. Epidemiology, cytogenetics and features. Human Genetics, 44, 227-275.

[2] Udwin, O. and Dennis, J. (1995) Psychological and behaviour phenotypes in generally determined syndromes: A review of research findings. In: G. O'Brien and W. Yules, Eds., Behavioural phenotypes, Mac-Keeith Press, London, 90-208.

[3] Wu, Q., Niebuhr, E., Yang, H. and Hansen, L. (2005) Determination of the "critical region" for cat-like cry of Cri-du-Chat syndrome and analysis of candidate genes by quantitative PCR. European Journal of Human Genetics, 13, 475-485. doi:10.1038/sj.ejhg.5201345

[4] Cerruti Mainardi, P., Perfumo, C., Calì, A., Coucorde, G., Pastore, G., Cavani, S., Zara, F., Overhauser, J., Pierluigi, M. and Dagna Bricarelli, F. (2001) Clinical and molecular characterization of 80 patients with $5 \mathrm{p}$ deletion: Genotype-phenotype correlation. Journal of Medical Genetics, 38, 417-420.

[5] Silber, D.L., Engel, E. and Merrill, R.E. (1966) So-called "cri du chat syndrome". American Journal of Mental Deficiency, 71, 152-154.

[6] Cornish, K.M. (1996) The neuropsychological profile of Cri-du-Chat syndrome without significant learning disabilities. Developmental Medicine \& Child Neurology, 38, 941-944. doi:10.1111/j.1469-8749.1996.tb15050.x

[7] Kristoffersen, K.L. (2008) Speech and language development in cri du chat syndrome: A critical review. Clinical Linguistics \& Phonetics, 22, 443-457. doi:10.1080/02699200801892108

[8] Cornish, K.M. and Pigram, J. (1996) Developmental and behavioural characteristics of Cri-du-Chat syndrome. Archives of Disease in Childhood, 75, 448-450. doi:10.1136/adc.75.5.448

[9] Cornish, K.M. and Munir, F. (1998) Receptive and expressive language skills in children with Cri-du-Chat syndrome. Journal of Communication Disorders, 31, 7381. doi:10.1016/S0021-9924(97)00052-X
[10] Pizzamiglio, M.R., Piccardi, L. and Guariglia, C. (2002) Asymmetries in neuropsychological profile in Cri-duChat syndrome. Euresco Conference. Brain Development and Cognition in Human Infants. Emergence of Social Communication: Hands, Eyes, Ears, Mouth. Acquafredda Di Maratea, 7-12 June 2002.

[11] Cornish, K.M. (1996) The neuropsychological profile of Cri-du-Chat syndrome without significant learning disabilities. Developmental Medicine \& Child Neurology, 38, 941-944. doi:10.1111/j.1469-8749.1996.tb15050.x

[12] Tamraz, J., Rethoré, M.O., Lejeune, J., Outin, C., Goepel, R., Stievenart, J.L., Iba-Zizen, M.T., Cabanis, E.A. and ARSEP (Association pour la recherche sur la sclérose en plaques, Paris) (1993). Morphométrie encéphalique en IRM dans la maladie du Cri du Chat. A propos de sept patients, avec revue de la littérature. Annales de Génétique, 36, 75-87.

[13] Cornish, K.M., Cross, G., Green, A., Willatt. L. and Bradshaw, J.M. (1999) A neuropsychological-genetic profile of atypical cri du chat syndrome: Implications for prognosis. Journal of Medical Genetics, 36, 567-570.

[14] Griffiths, R. (1986) The abilities of babies. The Test Agency, London.

[15] Caselli, M.C. and Casadio, P. (1995) Il primo vocabolario del bambino. Guida all'uso del questionario MacArthur per la valutazione della comunicazione e del linguaggio nei primi due anni di vita. Franco Angeli Editore, Milano.

[16] Wechsler, D. (1973) WPPSI scala wechsler a livello prescolare e di scuola elementare. Organizzazioni Speciali, Firenze.

[17] Dunn, L.M. and Dunn, L. (1981) Peabody picture vocabulary test. American Guidance Service, Mimnesota.

[18] Chilosi, A.M. and Cipriani, P. (1995) Test di Comprensione grammaticale per bambini. Edizioni del Cerro, Tirrenia.

[19] Slobin, D.I. (1985) Crosslinguistic evidence for the language-making capacity. Lawrence Erlbaum Associates, Mahwah.

[20] Bortolini, U. (1995) Prove per la valutazione fonologica del linguaggio infantile. Tipografia veronese, Padova.

[21] Beery, K.E. and Buktenica, N.A. (1989) Developmental test of visual-motor integration: Administration, scoring and teaching manual. Modern Curriculum Press, Cleveland.

[22] Preda, C. (2000) V.M.I. developmental test of visual motor integration. Firenze.

[23] Sohner, L. and Mitchell, P. (1991). Phonatory and phonetic characteristics of prelinguistic vocal development in cri du chat syndrome. Journal of Communication Disorders, 24, 13-20. doi:10.1016/0021-9924(91)90030-M 